\title{
O DIREITO DA CRIANÇA E DO ADOLESCENTE E A EXPERIÊNCIA DE EXTENSÃO UNIVERSITÁRIA DURANTE A PANDEMIA ${ }^{1}$
}

\author{
THE RIGHTS OF CHILDREN AND ADOLESCENTS AND THE \\ EXPERIENCE OF UNIVERSITY EXTENSION DURING THE PANDEMIC
}

\section{Rosane Leal da Silva ${ }^{2}$}

\section{RESUMO}

A educação jurídica deste século exige a conexão entre teoria e prática, com a criação de oportunidades de diálogo dos saberes que se produzem na academia e na sociedade. Essa aproximação ganha relevo quando se refere de tema sensível, como o Direito da Criança e do Adolescente, a partir do qual se indaga sobre os direitos fundamentais impactados em decorrência da pandemia da COVID-19 e se, nesse contexto, seria possível dar sequência às atividades de extensão, propostas na disciplina. Pautada em metodologia de pesquisa-ação, o artigo demonstra a possibilidade de a Universidade fazer-se presente com ações de extensão desenvolvidas por meio de redes sociais do Laboratório de Extensão do Curso de Direito.

Palavras-chave: ações de extensão, infância e adolescência, redes sociais.

\section{ABSTRACT}

The legal education of this century requires the connection between theory and practice, with the creation of opportunities for dialogue of knowledge produced in academia and society. This approach gains importance when it refers to a sensitive issue, such as the Rights of Children and Adolescents, from which one inquires about the fundamental rights impacted as a result of the COVID-19 pandemic and whether, in this context, it would be possible to continue the extension activities, proposed in the discipline. Based on action-research methodology, the article demonstrates the possibility of the University being present with extension actions developed through social networks of the Extension Laboratory of the Law Course.

Keywords: extension actions, childhood and adolescence, social networks.

1 Relato de experiência na Disciplina Extensionista Direito da Criança e Adolescente.

2 Doutora em Direito pela UFSC, professora do Curso de Direito da UFN, onde o trabalho foi produzido. E-mail: rosanelealdasilva@ufn.edu.br 


\section{INTRODUÇÃO}

A educação jurídica nos tempos atuais passa por uma transição paradigmática. Ao mesmo tempo que as velhas práticas persistem e são continuamente denunciadas em face da exaustão do modelo de ensino-aprendizagem, as novas estratégias metodológicas ainda não surtem os efeitos esperados, sobretudo porque atravessados por um período de pandemia global que desafia a educação.

Entre incluídos e excluídos do sistema educacional, há um contingente enorme de estudantes que ainda tenta vencer a crise, tirando o melhor partido das situações, problemas e oportunidades que se revelam neste período histórico. Para esses, conseguir manter uma conexão que permita assistir às aulas é um desafio constante.

É inegável, no entanto, que ao lado dos problemas já conhecidos, derivados do ensino remoto, novos se apresentam quando se trata de estimular os estudantes a manterem o foco nos estudos, driblando as incertezas e o medo, especialmente quando tudo a sua volta parece apontar insistentemente no caminho das incertezas. Em meio a um cenário de emergência sanitária global não experenciado por esta geração, deve-se atentar para a promoção de uma formação que reflita sobre os problemas sociais e a necessidade de o Curso de Direito aproximar-se da realidade social, ainda que momentaneamente mediado por tecnologias.

Neste contexto, questionou-se sobre os principais direitos fundamentais de crianças e adolescentes se mostravam mais vulneráveis em meio ao isolamento social e quais os conteúdos de fácil compreensão poderiam ser produzidos. Na tentativa de responder a esta indagação, os estudantes foram instigados a investigar o tema em bibliografia indicada e matérias publicadas nas mídias digitais do Curso de Direito.

Nesta perspectiva de formação e diante da necessidade de cumprir as exigências das Diretrizes Curriculares para os Cursos Jurídicos que se apresenta este trabalho, cujo objetivo é expor alguns resultados realizados no projeto de extensão "Direito da infância e adolescência conectando saberes", com foco na Educação jurídica em formato digital, voltada para à sensibilização e difusão dos direitos de crianças e adolescentes, desenvolvido no ano de 2020 na disciplina de Direito da Criança e do Adolescente da Universidade Franciscana. Tal projeto se liga à linha de pesquisa Direito Constitucional Aplicado, gestão de pessoas e de processos e ao Programa de Extensão Institucional denominado Direito, Políticas Públicas e Diversidade.

\section{O PAPEL DA EXTENSÃO NA EDUCAÇÃO JURÍDICA.}

Pensar em educação jurídica pressupõe, de maneira anterior, reconhecer que a educação é um direito fundamental, previsto na Constituição Federal de 1988, nos artigos 205 ao 214. Conforme estabelecido no art. 205, a educação é um direito subjetivo de todos, constituindo-se em dever de o Estado 
promovê-la em cooperação com a sociedade, visando ao pleno desenvolvimento da pessoa (BRASIL, 1988). Este pleno desenvolvimento não será alcançado somente a partir do domínio cognitivo, pois a completa formação pressupõe o desenvolvimento de outros domínios, a exemplo do afetivo e do psicomotor, tal como propagado pela Taxonomia de Bloom, em releitura realizada por Ferraz e Belhot (2010).

A formação atenta ao desenvolvimento dessas competências mostra-se comprometida com o desenvolvimento de habilidades e competências, o que exige a releitura crítica dos papeis tradicionalmente ocupados por docentes e discentes. Quanto aos primeiros, devem estar abertos à contínua aprendizagem e formação, especialmente em tempos tão dinâmicos e desafiadores de educação híbrida. Aliado a isso e seguindo os passos de Perrenoud (2000, p. 23-24), o professor deve ser capaz de organizar e dirigir atividades partindo do pressuposto de que cada pessoa aprende de uma maneira específica e ainda que todos escutem à mesma explicação verbalizada pela professora, cada um assimilará o conteúdo e o tornará significativo ou não a partir de quanto o tema diz para si, seu campo afetivo, seus interesses. Segundo Perrenoud (2000, p. 24), os professores precisam ter consciência de que "a padronização aparente da situação é uma ficção e que existem tantas situações diferentes quanto alunos. Cada um vivencia a aula em função de seu humor e sua disponibilidade, do que ouve e compreende conforme seus recursos intelectuais [...]". Portanto, cada professor deve questionar-se sobre as situações de aprendizagem que cria, pois do contrário estará em ingênua posição de quem imagina que os estudantes aprendem, quando na realidade este processo não se desenvolve. E novamente Perrenoud (2000, p. 26) oferece diretrizes para dar sentido ao processo de aprendizagem ao afirmar que os professores precisam mobilizar competências globais com proposição de "situações amplas, abertas, carregadas de sentido e regulação, às quais requerem um método de pesquisa, de identificação e de resolução de problemas”. Para tanto, é preciso não só conhecer profundamente a disciplina e seus conteúdos, mas ser capaz de atuar a partir da representação dos estudantes, levar em conta o quanto aquele conteúdo os sensibiliza, envolvendo os discentes na produção do material, desde sua concepção até sua entrega. Pensado a partir desse prisma, o lugar da avaliação estanque e calcada em habilidades meramente cognitivas parte-se para um processo que é carregado de significados, capaz de operar mudanças comportamentais nos sujeitos participantes do processo.

E não poderia ser diferente, pois a sociedade exige, na atual quadra histórica, profissionais com outro perfil, capazes de responder a realidades complexas, com poder de criação e habilidade de trabalhar em grupo. Portanto, para obter esse resultado os partícipes da relação educativa devem ser instigados a compreender os processos sociais nos quais estão inseridos e interagir com a sociedade.

Para tanto, essencial que a educação se desenvolva a partir do tripé ensino, pesquisa e extensão, cuja indissociabilidade deve ser promovida pelas instituições de ensino superior. Segundo Machado e Arruda (2018, p. 4), "A noção de indissociabilidade implica que o ensino, a pesquisa e a extensão estão intrinsecamente articulados entre si, e se fazem presentes como práticas pedagógicas, seja como atividades de origem e/ou fim." 
Assim, impossível pensar nos processos educativos sem destacar o papel da extensão, que passou por inúmeras fases. Para compreender o atual estágio e evitar incorrer em erros do passado é imperioso lançar um olhar sobre seu percurso de desenvolvimento.

Conforme lições de Frutuoso (2020, p. 40), as origens da extensão estão no Decreto $n^{0} 19.851$, de 11 de abril de 1931, cujo artigo 109 mencionava a "extensão universitária destinada à difusão de conhecimentos filosóficos, artísticos, literários e científicos, visando ao benefício do desenvolvimento individual e coletivo". Segundo ele, em 1960 foram fixadas normas para o seu funcionamento e organização no ensino superior, etapa na qual deveria proporcionar atividades que resultasse na melhoria da vida comunitária.

Considerando o período que se vivia, também a extensão deveria contribuir para a formação cívica, confundindo-se com prestação de serviços e assistencialismo. O próximo passo ocorreu em 1975, com a criação da coordenação de atividades de Extensão. Neste momento o conceito de extensão mostra-se um pouco mais permeável a dialogicidade (FRUTUOSO, 2020, p. 40), embora não seja suficiente para evitar as críticas de Paulo Freire, que em 1978 publica uma obra criticando o modelo adotado, no qual as universidades levariam o saber produzido em seus muros para as comunidades menos favorecidas, consideradas como meros depositários do saber intelectual produzido nas universidades, que sequer se preocupavam com as necessidades do público com quem interagiam. O autor criticava esta concepção, resumida no ato de depositar informes na população e perpetuar os valores de uma cultura dada, distanciando-se da educação como prática da liberdade (FREIRE, 1983, p. 53).

A partir das lições de Dias (2021, p. 24) é possível perceber que na década de 80 as universidades foram muito tensionadas pelas demandas e pressões dos movimentos sociais, o que encontrou eco em vozes de dentro das instituições e resultou na ressignificação da extensão. Este movimento ganhou sustentação do Fórum Nacional de Pro-Reitores de Extensão que, em 1987, reconheceu a extensão como uma "via de mão dupla", na qual a academia deveria atuar junto à sociedade para reelaborar o conhecimento acadêmico, única forma de superar o assistencialismo que orientava a extensão. Reconhecia-se a necessidade de construir um novo fluxo de troca de saberes.

A redemocratização que emergia naquela quadra histórica, no entanto, não contribuiu de maneira efetiva para valorização da concepção da extensão, prevista muito timidamente no art. 207 da Constituição Federal de 1988. Seu maior espaço e valorização ocorreu com a Lei das Diretrizes e Bases da Educação Nacional (LDB), que dentre as finalidades da educação superior contemplou a extensão que, segundo a promessa normativa, deve ser aberta à participação da população, resultantes da criação cultural e da pesquisa científica e tecnológica desenvolvida na instituição superior (BRASIL, 1996).

Encontrar o lugar da extensão nos cursos superiores sempre foi tarefa difícil e no Fórum de Pró-reitores de Extensão das Universidades Públicas, realizado em 2012, foi construído um novo conceito de extensão, que resultou da interpretação do Plano Nacional de Extensão Universitária, 
publicado no ano de 1999. Neste momento reafirmou-se o entrelaçamento indissociável entre ensino, pesquisa e extensão como um processo interdisciplinar que promove a interação entre a universidade e a sociedade (DIAS, 2021, p. 25).

A maior transformação na área jurídica, segundo Dias (2021, p. 28) iniciou-se em decorrência da Portaria 1.886, de 1994, cuja redação apresenta a integração da extensão como uma possibilidade de releitura da atuação jurídica em sala de aula. Iniciava-se assim, a caminhada rumo à interdisciplinaridade, com dimensões teóricas e práticas nos currículos. Posteriormente, a Resolução nº 09, de 2004 previu que os cursos de educação jurídica deveriam ter uma visão interdisciplinar visando à sólida formação humanística que permitisse aos estudantes interpretar, valorizar e interagir com os processos sociais. Essa preocupação se materializa no art. $2^{\circ}$ das Diretrizes Curriculares Nacionais para os Cursos de Direito, o qual prevê o incentivo à pesquisa e à extensão como prolongamento das atividades de ensino (DIAS, 2021, p. 28-29).

O passo seguinte ocorreu em 2018, com a edição da Resolução ${ }^{0}$ 7, do Conselho Nacional de Educação que apresenta as diretrizes nacionais para educação no ensino superior. No art. $3^{\circ}$, a extensão passa a ser integrada à matriz curricular e à organização da pesquisa, constituindo-se em processo interdisciplinar, político educacional, cultural científico, tecnológico e que deve promover a interação transformadora entre a universidade e os outros setores da sociedade. (BRASIL, 2018).

Este cenário de transformações no ensino jurídico também foi impactado pela Resolução $\mathrm{n}^{\mathrm{o}} 5$ de 2018, do Conselho Nacional de Educação, que instituiu as diretrizes curriculares nacionais do curso de graduação em Direito e pela Resolução $n^{\circ}$ 7, de 18 de dezembro do mesmo ano, que dispôs sobre as diretrizes para extensão na educação superior brasileira. Segundo este último documento fixou-se o percentual de $10 \%$ da carga-horária dos cursos para execução de atividades de extensão. Como consequência, o projeto pedagógico dos cursos deveria inserir as seguintes modalidades de extensão: programas, projetos, cursos e oficinas, eventos e prestação de serviços. Como se percebe, há uma gama de atividades que podem ser direcionadas ao entrelaçamento entre universidade e sociedade.

Renova-se, dessa forma, a responsabilidade dos cursos jurídicos, que devem incorporar a preocupação com ações voltadas as áreas de grande pertinência social e é com esse compromisso que se apresenta a curricularização da extensão na disciplina de Direito da Criança e Adolescente, da Universidade Franciscana.

\section{METODOLOGIA DE TRABALHO EXTENSIONISTA}

A atividade de extensão valeu-se de metodologia qualificada como Pesquisa-Ação, eleita em razão da possibilidade de essa metodologia aliar pesquisa e ao mesmo tempo ter o potencial de alterar a prática. Segundo Tripp (2005, p. 445-446), “É importante que se reconheça a pesquisa-ação como um dos inúmeros tipos de investigação-ação, que é um termo genérico para qualquer 
processo que siga um ciclo no qual se aprimora a prática pela oscilação sistemática entre agir no campo da prática e investigar a respeito dela". Segundo explicitado pelo autor, ao utilizar esta estratégia "Planeja-se, implementa-se, descreve-se e avalia-se uma mudança para a melhora de sua prática, aprendendo mais, no correr do processo, tanto a respeito da prática quanto da própria investigação" (TRIPP, 2005, p. 446).

O percurso metodológico eleito partiu de abordagem conteudística realizada em aulas remotas expositivo-dialogadas, encontros precedidos de leituras e indicação de documentários. No momento do encontro virtual discutiu a legislação aplicável e seu contraste com a produção literária na área, o que foi combinado com a realização de trabalhos grupais e uso de metodologias ativas, com pesquisa e narrativas de julgados. Essas estratégias de ensino contribuíram para os estudantes se apropriarem dos temas tratados na disciplina, desenvolvendo condições de eleger o assunto sobre o qual seria intensificada a pesquisa, para fins de preparação de materiais voltados às ações de extensão. Neste momento, valendo-se dos ensinamentos de Perrenoud (2000, p. 26) tentava-se, a partir de abordagens amplas e abertas, permitir que os estudantes se identificassem com determinado tema que lhes parecesse significativo para, então, aprofundar os estudos em atividade grupal de pesquisa.

$\mathrm{Na}$ fase de pesquisa era impositivo realizar levantamento normativo e bibliográfico, submetendo os escritos à análise preliminar da professora, acompanhado da proposta de ação de extensão, que poderia ser efetivada por meio da montagem de vídeos ou podcasts, elaboração de cartilhas virtuais, cartazes para divulgação online ou outro formato, a escolha da equipe responsável.

A produção do conteúdo de extensão permitiu que os estudantes refletissem sobre o próprio ensino e as bases epistemológicas daquele conhecimento, que muitas vezes se encontra desconectado das vivências e da realidade dos destinatários da legislação, quais sejam, as crianças e adolescentes que são os sujeitos de direitos. Numa forma de valorizar o engajamento e a produção das equipes, todos os grupos apresentaram os resultados da atividade extensionista aos demais colegas, atividade que foi pontuada com metade da terceira nota avaliativa. Os melhores trabalhos integram um Livreto Virtual da Extensão, com maior visibilidade nas redes sociais do Curso de Direito.

Destaque-se que a estratégia de elaboração de conteúdo para divulgação online se tornou uma imposição desde março de 2020, em decorrência da situação de emergência sanitária global em curso desde então. Diante disso, as atividades antes realizadas em visitação e palestras às escolas, assim como as interações em espaços públicos e campanhas de esclarecimento promovidas a partir do contato com a população migraram para o ambiente virtual e são divulgadas no Blog do Curso de Direito e na conta do Laboratório de Extensão no Instagram. 


\section{O DIREITO DA CRIANÇA E DO ADOLESCENTE: BREVE APORTE PARA COM- PREENSÃO DO TEMA.}

O Direito da Criança e do Adolescente se constituí em um ramo do Direito relativamente recente, pois ainda que a primeira legislação brasileira a tratar do tema datasse de 1927, começo do século XX, o paradigma utilizado naquele momento histórico não se confunde com os princípios e valores orientadores deste ramo do Direito na atualidade.

Com efeito, o paradigma anterior, denominado "menorista" ou da "situação irregular", tratava crianças e adolescentes como "menores", termo utilizado para se referir a quem era privado de capacidade e sem condições de emitir qualquer vontade válida ao mundo jurídico, reduzidos à condição de objeto de intervenção da sua família ou do Estado. A legislação produzida ao longo do Século XX ora optava por respostas assistencialistas, ora adotava o viés da defesa Social, retirando das ruas e lugares públicos aquelas crianças e adolescentes consideradas em situação irregular por serem vítimas de violência e abandono ou por terem realizado atos infracionais. Indistintamente à situação de abandono ou de prática de ato infracional, eram institucionalizados para que as ruas e a sociedade ficassem a salvo.

Esta concepção começou a ser superada normativamente com a previsão do art. 227 da Constituição Federal, segundo a qual a família, a sociedade e o Estado devem promover, com prioridade absoluta, os direitos das crianças e adolescentes. Ao lado da proteção integral, estabeleceu-se o entendimento de que esses sujeitos de direitos deveriam ter prioridade absoluta no atendimento e na promoção de seu desenvolvimento integral.

Por suas características, voltada à compreensão do tratamento social, econômico e jurídico da infância, esta disciplina se mostra bastante permeável a interação entre teoria e prática. Visa a discutir o papel dos atores encarregados da proteção integral, a insuficiência de suas ações e provoca os estudantes de Direito a desenvolverem soluções para a promoção da infância a partir de um marco de atuação que se mostre alinhado com a Convenção Internacional dos Direitos da Criança, de 1989; com a Constituição Federal de 1988, que adotou a proteção integral e com os princípios e valores que orientam a Lei nº 8.069, de 1990, denominada Estatuto da Criança e do Adolescente.

Conforme prevista na Carta Constitucional, a Doutrina da Proteção Integral inaugurou um sistema misto, no qual os membros da família, os demais integrantes da sociedade civil e o Estado devem zelar e promover os direitos fundamentais de crianças e adolescentes. Um ator não retira os poderes ou interfere nos espaços de atuação dos demais, o que impõe uma releitura do Direito da Criança e do Adolescente, superando-se o modelo de participação sucessivo ou residual em direção a um modelo colaborativo e de co-participação, no qual a Universidade também tem muito a contribuir.

Com efeito, o dever de promover a proteção integral impõe aos adultos dever jurídico de dupla face: ao mesmo tempo em que têm que se abster de violar os direitos de crianças e adolescentes, 
devem promover o respeito aos seus direitos fundamentais, amplamente positivados no Brasil. conforme destaca Veronese (1999, p. 120-121) ao cotejar o texto do artigo 16, da Convenção Internacional sobre os Direitos da Criança, com os artigos correspondentes, previstos na Lei 8.069/90, há alinhamento entre o documento internacional e o diploma legal nacional, destacando-se o direito à vida e integridade física, o direito à integridade psíquica, direito à integridade moral, constando nos dois documentos o reconhecimento de que deve haver o respeito e a promoção a esses direitos, tratados em perspectiva de sua interdependência e indivisibilidade. A proteção integral requer a satisfação de todos esses direitos, pois basta a violação a um deles para que seja atingida negativamente a dignidade humana do infante ou adolescente.

E aqui vale lembrar, nas palavras de Sarlet (2011, p. 30), a indissociável relação que existe entre dignidade humana e os direitos fundamentais e, ainda que o consenso sobre o conteúdo da dignidade se mantenha em constante discussão em razão de ser vago e aberto, pode-se afirmar que se trata de "qualidade integrante e irrenunciável da própria condição humana", sendo-lhe inerente. (SARLET, 2011, p. 52).

Portanto, crianças e adolescentes também possuem sua dignidade, que só será concretizada na medida que os seus direitos fundamentais forem considerados. Tal afirmativa parece simples e até mesmo óbvia, mas é carregada de sentido se analisado no contexto histórico no qual se desenvolveu este ramo do Direito, que por séculos se manteve preso ao paradigma que objetificava e desconsiderava os direitos dos infantes.

A viragem normativa começou por influência internacional: os bons ventos que sopravam dos debates que animaram a elaboração da Convenção Internacional sobre os Direitos da Criança, editada em 1989 no marco da Organização das Nações Unidas indicavam que era tempo de reconhecer crianças e adolescentes como sujeitos de direitos, cuja promoção e proteção deveria ficar a cargo da família, da sociedade e do Estado. Este comando foi assimilado pela Constituição Federal, em seu artigo 227 e irradia efeitos no âmbito nacional para todo o ordenamento jurídico.

Os direitos fundamentais de crianças e adolescentes passam a ser formal e explicitamente reconhecidos como condição de possibilidade para o alcance da dignidade humana, cuja promoção é tarefa de todos e deve ser realizada em homenagem à solidariedade. Ao tratar do tema da solidariedade relacionada à infância e adolescência, Sousa (2020, p. 137) sustenta que a efetivação dos direitos fundamentais exige ações articuladas e responsabilidades compartilhadas entre a família e a sociedade civil, formando-se um novo laço entre corpo social e Estado que é baseado na solidariedade. Assim, a dicotomia público/privada erguida na modernidade cederia espaço para a solidariedade, que "implica no comprometido agir individual e coletivo das instâncias privadas para a garantia dos direitos de crianças e adolescentes no marco da proteção integral”. 
Inspirados pelo princípio da solidariedade e impactados pelo momento pandêmico vivido em âmbito global, cujos reflexos são ainda mais nefastos para quem se encontra em peculiar fase de desenvolvimento, vários grupos de estudantes elegeram temas voltados à salvaguarda de direitos no período da pandemia, como se verá na sequência.

\section{AÇÕES DE EXTENSÃo EM DIREITO EMOLdURADAS PELO CENÁRIO DE PANDEMIA}

O direito fundamental à educação, previsto na Constituição Federal e reforçado no art. 53, da Lei $n^{\circ}$ 8.069, de 1990 esteve na pauta de atenção dos estudantes do Curso de Direito. Assim, levando em conta que a educação migrou para o ambiente digital durante o ano de 2020, os estudantes preocuparam-se com os processos de exclusão de quem não tem acesso às tecnologias de informação e comunicação, bem como discutiram o papel na família no acompanhamento dos infantes e adolescentes, tanto na realização de atividades quanto nos momentos de lazer. Como resultado, foi produzido um cartaz virtual, com sugestão de conteúdo audiovisual com conteúdo adequado à formação de crianças e adolescentes, conforme abaixo evidenciado.

Figura 01 - Trabalho de extensão sobre educação na pandemia.

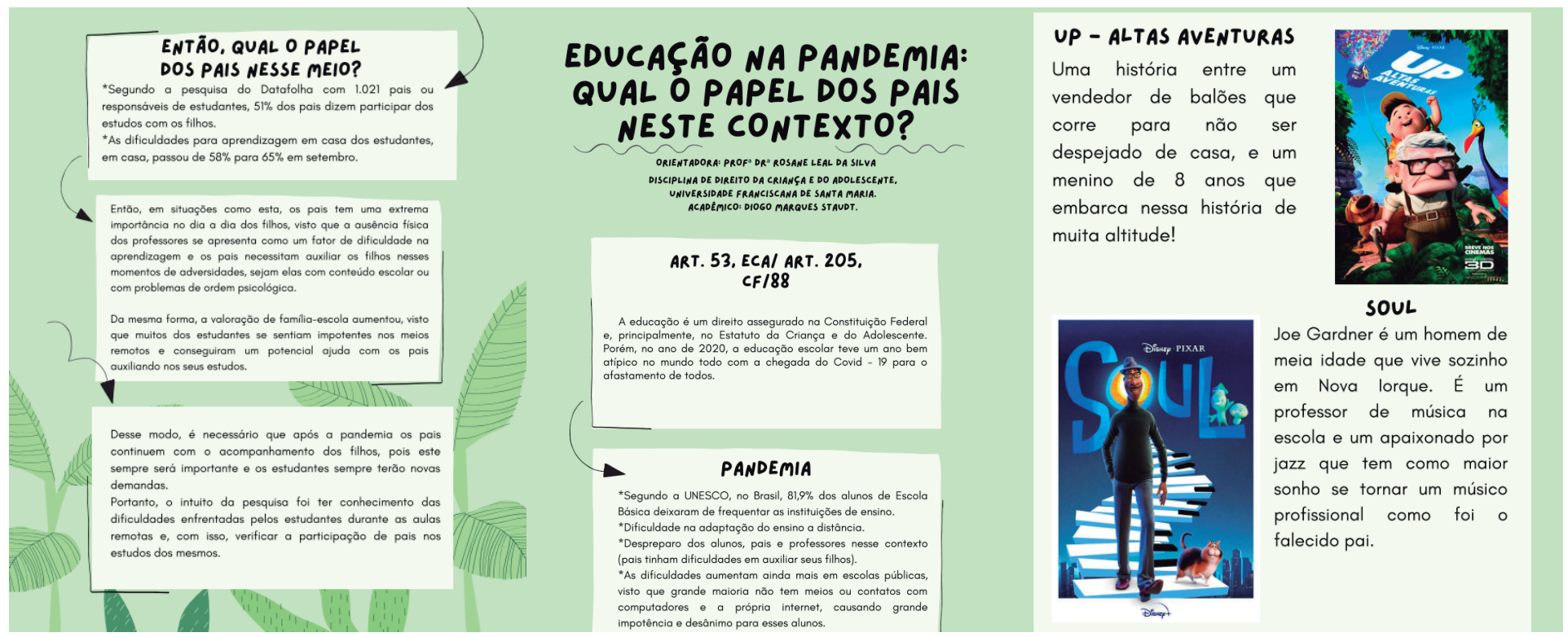

Fonte: Trabalho produzido por Diogo Marques Staudt

Outro tema valorizado pelos estudantes de Direito foi o direito fundamental à saúde, previsto no Estatuto da Criança e do Adolescente nos artigos $7^{\circ}$ a 14. 
Compreendendo a essencialidade desse direito e conscientes dos efeitos negativos que as campanhas de desinformação produziram, resultando no retorno de muitas doenças já erradicadas, foi produzido um cartaz virtual sobre a importância da vacinação, conforme demonstrado abaixo:

Figura 02 - Trabalho de extensão sobre vacinação.

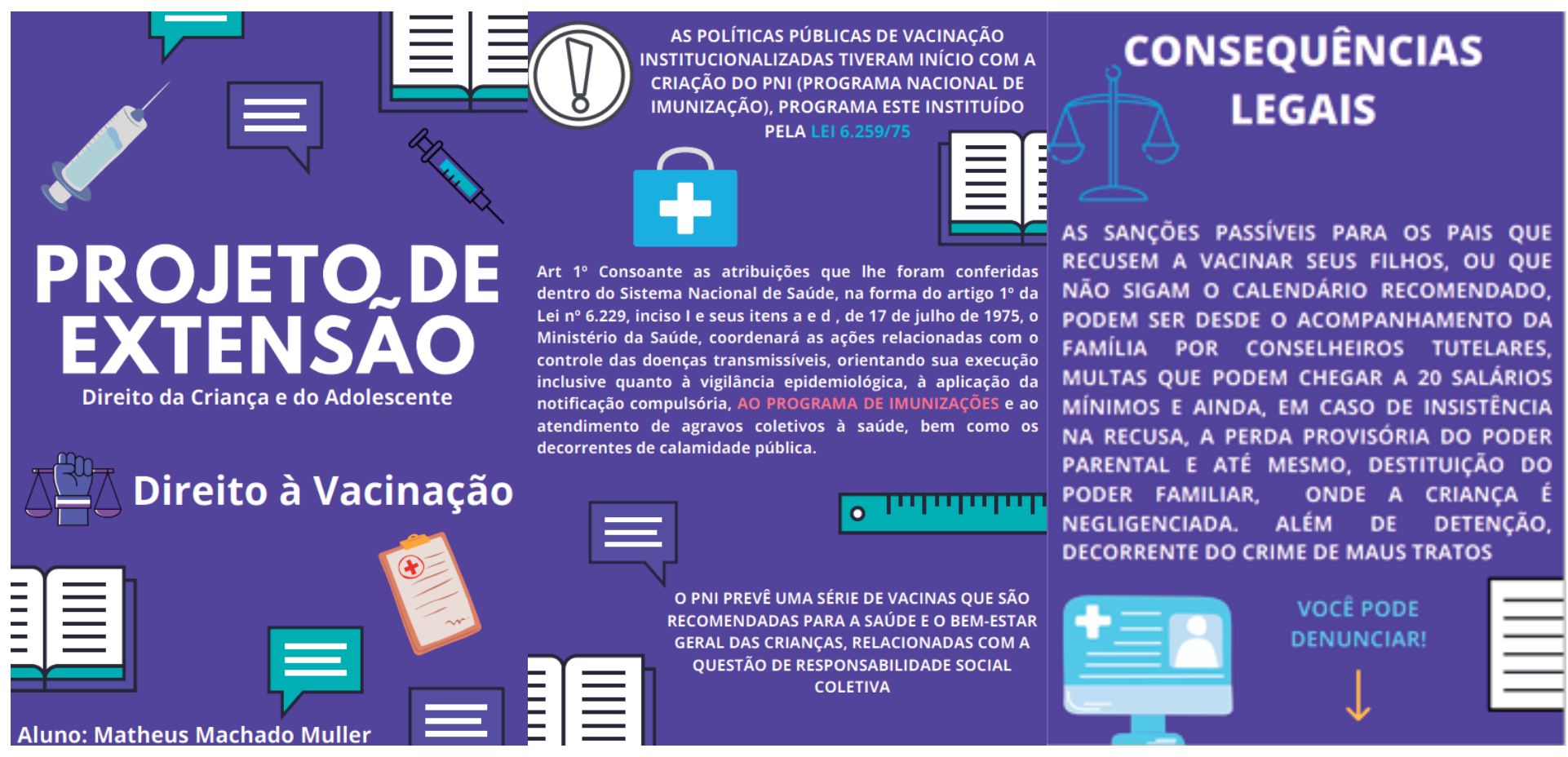

Fonte: Fragmentos do cartaz digital de Matheus Machado Muller

Sabe-se que o tema da obrigatoriedade da vacinação de crianças é controvertido sob vários pontos de vista, tanto ético quanto cultural e religioso. No entanto, de acordo com as normas vigentes, há uma obrigatoriedade de vacinar as crianças, o que ocorre desde meados dos anos setenta do século passado, quando foi editada a Lei $n^{0}$ 6.259, de 1975, que instituiu o Programa Nacional de Imunizações (PNI), com vacinação obrigatória e gratuita. Segundo o art. $3^{\circ}$ da referida lei, a competência na elaboração do PNI é do Ministério da Saúde. Muitos médicos e profissionais da saúde passa a defender a vacinação e esse movimento, como explicam Barbieri, Couto e Aith (2017, p. 2) acaba por levar o tema para o âmbito do próprio

Conselho Federal de Medicina, cuja regulamentação orientava que, diante da recusa dos pais em realizar a vacina "o melhor interesse do menor deve prevalecer e a responsabilidade do médico e da instituição hospitalar existe independente da dos pais". Como consequência, o profissional deveria realizar a "notificação e a tomada de decisão a favor da proteção desse menor, que está sofrendo situação de desamparo". 
Para além dos embates e das alegações de que o Estado não pode "usurpar" o direito de os pais escolherem se querem ou não vacinar os filhos, cabe indagar se os pais têm o direito de decidir sobre a vida dos filhos, colocando suas vontades e ideologias contra as indicações científicas consolidadas na área. Portanto, defende-se que a abordagem do tema transcendendo o caráter individual da tomada de decisão do núcleo familiar e avança também no âmbito do interesse coletivo, sobretudo porque essa decisão do núcleo familiar pode trazer reflexos negativos para outras crianças, que podem ser contaminadas e ter sua saúde comprometida irremediavelmente.

Outro tema que mobilizou os estudantes foi a violência sexual infantil, tanto a presencial quanto aquela realizada online. A violência, que se constitui crime dos mais repudiáveis, também se intensificou durante a pandemia, período no qual muitas crianças se mantiveram isoladas no ambiente familiar, sem frequentar a escola, local onde usualmente o rastro devastador dessa violação é percebido por professores e orientadores pedagógicos. Esses profissionais não somente são capacitados para perceber os sinais físicos de violência, como também estão obrigados, pelo art. 245 do Estatuto da Criança e do Adolescente, a denunciar as situações de violência constatadas.

Uma das formas de violência que também teve exponencial crescimento, segundo dados da Safernet Brasil (2021) foi a pornografia infantil online, que dobrou em comparação ao ano de 2019 e teve recorde histórico desde que a Organização Não-Governamental começo a colher indicadores, no ano de 2006. Em 2020 houve 98.244 denúncias anônimas de sites e páginas com pornografia infantil na internet, o que indica que o maior uso da internet torna crianças e adolescentes mais vulneráveis a essas violências, tipificadas nos arts. 240 e 241, da Lei no 8.069 de 1990.

A mera tipificação, no entanto, não é suficiente para evitar a proliferação desse crime online, o que é agravado por inúmeros fatores, assim sumarizados a partir das contribuições de Silva (2019, p. 520) em estudo específico sobre o tema, a saber: a) o rápido desenvolvimento tecnológico; b) característica transnacional do delito; c) perfil do autor do ilícito, usualmente alguém que sabe usar as tecnologias e que se distingue do padrão visado pelas autoridades policiais; d) criação de novos aplicativos e ambientes, tal como ocorre com as camadas mais profundas da internet (deep web e dark web). A esses fatores se soma o desafio da pandemia, momento em que a socialidade e o processo educativo de milhões de crianças e adolescentes migraram para o ambiente virtual.

Portanto, nada mais oportuno do que produzir material sobre violência sexual, com orientações sobre sua identificação e prevenção, assim como propor medidas para a navegação segura dos infantes e adolescentes na internet, conforme se verá na sequência: 
Figura 03 - Trabalho de extensão sobre violência sexual infantil.

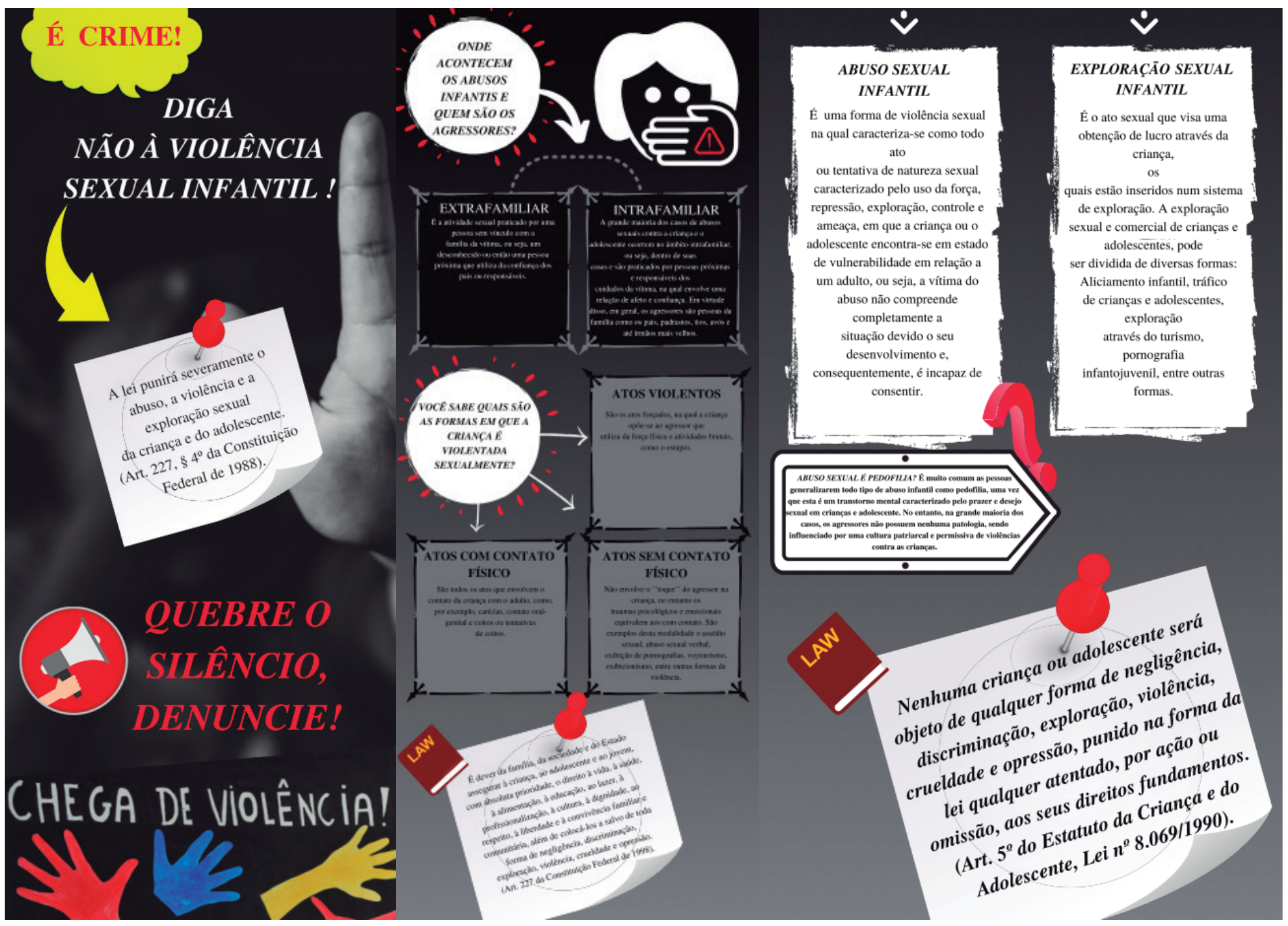

Fonte: fragmentos do infográfico elaborado pelos estudantes: Bruno Seeger, Celso Rosso e Marco Antônio.

Conforme evidenciado no trabalho abaixo, que também versou sobre o tema da violência, há distintas formas, atingindo inclusive crianças e adolescentes com deficiência. 
Figura 04 - Trabalho de extensão para enfrentamento da violência sexual contra crianças e adolescentes.
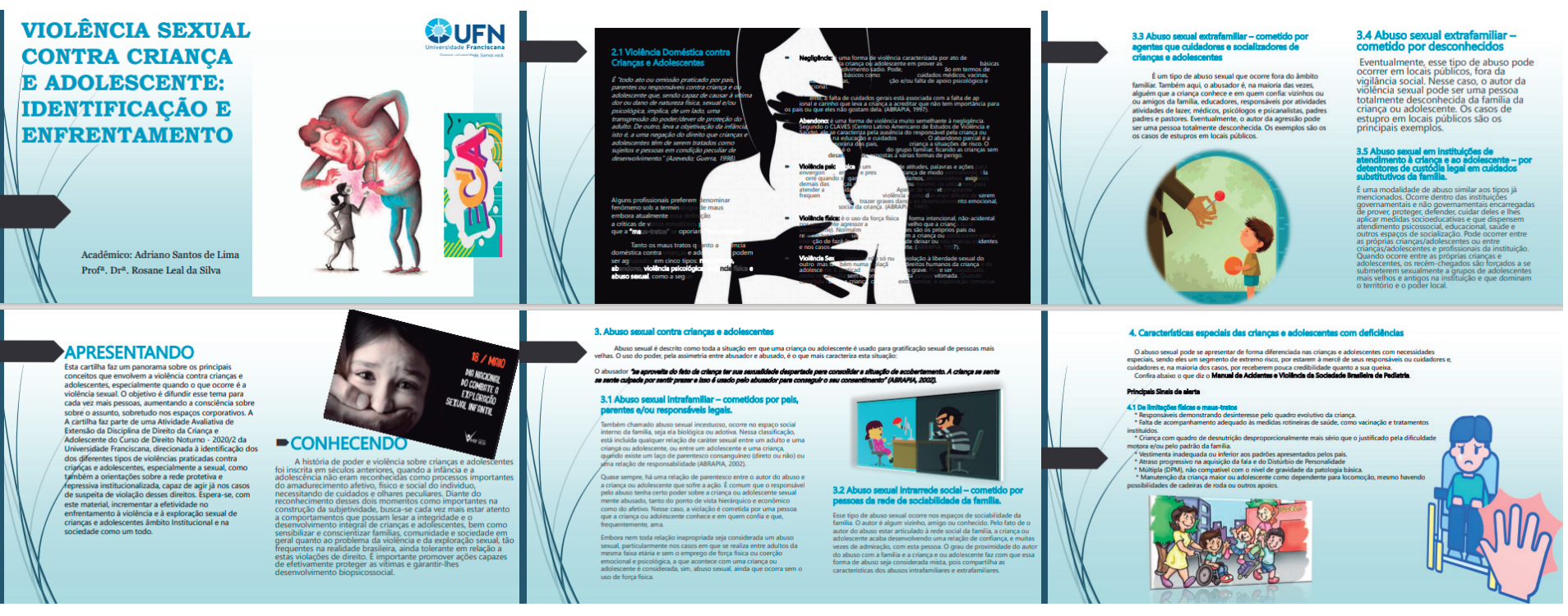

Fonte: fragmentos da cartilha digital criada por Adriano Santos de Lima.

Como visto pelos dados já evidenciados, em tempos de pandemia e sob a crença de que os filhos estavam seguros em casa, muitos pais não acompanharam a atividade dos filhos na internet, resultando num aumento dos casos de violência sexual online. Para despertar a curiosidade e sensibilizar os pais, foi proposta uma cartilha virtual sobre esse risco invisível:

Figura 05 - Trabalho de extensão sobre aliciamento online.

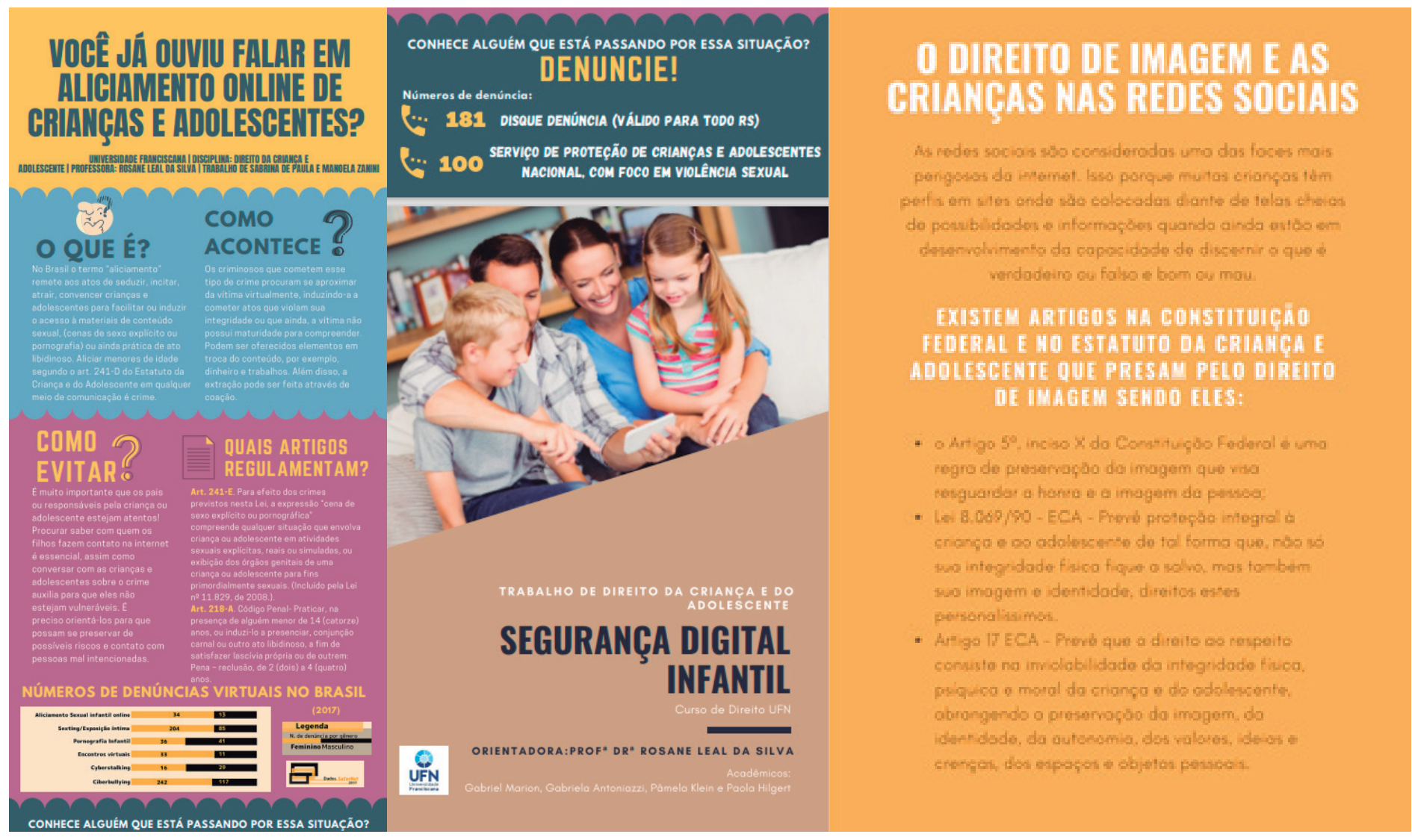

Fonte: Fragmentos do cartaz digital elaborado por Gabriel Marion, Gabriela Antoniazzi, Pâmela Klein e Paula Hilgert. 
A ideia que norteou o trabalho não foi exaurir o tema, o que seria impossível pela sua profundidade. Trata-se, antes de tudo, de provocar a reflexão para que as famílias possam atentar para a necessidade de orientação parental, o que deve ser feito baseado no diálogo e orientação da família.

\section{CONCLUSÃO}

Pensar e executar a curricularização da extensão em tempos de pandemia consiste em inegável desafio, posto que o isolamento coloca professores e discentes em distanciamento tanto entre si quanto daqueles que seriam os destinatários das práticas.

Apesar de todas as vicissitudes, as discussões de temas sensíveis sobre a infância, realizadas durante as aulas da disciplina de Direito da Criança e Adolescente despertaram a sensibilidade dos estudantes, que se sentiram provocados por determinados temas, mais significativosa eles. E isso por si só já pode ser considerado um aspecto positivo, a evidenciar que ao lado das competências cognitivas também foram desenvolvidos aspectos afetivos, na medida em que os estudantes se permitiram lançar um olhar atento e humano sobre a realidade de muitas crianças nesse tempo histórico sem precedentes. Instigados pelo tema dos direitos fundamentais em tempos de pandemia, mergulharam em exercício de pesquisa e trabalho grupal e, à medida em que aprofundavam na investigação também desenvolviam importantes aspectos relativos às competências psicomotoras. Posteriormente mobilizaram a criatividade e habilidades para o uso de recursos tecnológicos, o que se mostrou necessário para a elaboração dos produtos de extensão.

Ao fim de um ano tão peculiar e desafiador, comprovou-se que é possível fazer ações de extensão, mesmo que mediadas por tecnologias. O distanciamento, que serviu de pano de fundo para as reflexões, não impediu que os temas fossem pesquisados e aprofundados e, com um pouco de criatividade, temas relevantes foram traduzidos em linguagem simples e assumiram a forma de cartilhas digitais e infográficos, com importantes informações que foram veiculadas nos canais institucionais, com destaque para a divulgação no Instagram do Laboratório de Extensão. O ensino jurídico se reinventa e se humaniza, mostrando que pode ser provocador e sair da zona de conforto, ainda que em tempos de emergência sanitária global.

\section{REFERÊNCIAS}

BARBIERI, Carolina Luisa Alves; COUTO, Márcia Thereza; AITH, Fernando Mussa Abujamra. A (não) vacinação infantil entre a cultura e a lei: os significados atribuídos por casais de camadas médias de São Paulo, Brasil. Cadernos de Saúde Pública [online]. 2017, v. 33, n. 2. Disponível em: https://doi.org/10.1590/0102-311X00173315. Acesso em: 26 jun. 2021 
BRASIL. Constituição da República Federativa do Brasil de 1988. Brasília, 5 out. 1988. Disponível em: https://bit.ly/3vm92f8. Acesso em: 28 maio 2021.

BRASIL. Lei n 9.394, de 20 de dezembro de 1996. Estabelece as diretrizes e bases da educação nacional. Disponível em: https://bit.ly/2Z2kHn1. Acesso em: 20 jun. 2021.

BRASIL. Lei no 8.069, de 13 de julho de 1990. Dispõe sobre o Estatuto da Criança e do Adolescente e dá outras providências. Brasília, DF, 16 jul. 1990. Disponível em: https://bit.ly/3aQIokU. Acesso em: 05 jun. 2021.

DIAS, Renato Duro. Extensão universitária nos cursos de graduação em direito. Quaestio Iuris. v. 14, n. 01, Rio de Janeiro, 2021. p. 21-39. Disponível em: https://bit.ly/3BT3WsZ. Acesso em: 20 jun. 2021.

FERRAZ, Ana Paula do Carmo Marcheti; BELHOT, Renato Vairo. Taxonomia de Bloom: revisão teórica e apresentação das adequações do instrumento para definição de objetivos instrucionais. Gestão \& Produção [online]. 2010, v. 17, n. 2 p. 421-431. Disponível em: https://doi.org/10.1590/ S0104-530X2010000200015. Acesso em: 20 jun. 2021.

FREIRE, Paulo. Extensão ou comunicação? 7. ed. Rio de Janeiro, Paz e Terra, 1983.

FRUTUOSO, Tomé de Pádua. O processo de curricularização da extensão nos cursos de graduação do Instituto Federal de Santa Catarina - IFSC. Dissertação de Mestrado. Mestrado Profissional em Educação Profissional e Tecnológica em Rede Nacional (PROFEPT). Instituto Federal de Educação, Ciência e Tecnologia de Santa Catarina (IFSC), 2020.

PERRENOUD, Philippe. Dez novas competências para ensinar. Tradução: Patrícia Chittoni Ramos. Porto Alegre: Artes Médicas Sul, 2000.

SAFERNET BRASIL. Denúncias de Pornografia infantil cresceram 33,45\% em 2021, aponta a Safernet Brasil. Números seguem crescendo após recorde histórico de denúncias registrado em 2020. Disponível em: https://bit.ly/3jbVLki. Acesso em: 26 jun. 2021.

SARLET, Ingo Wolfgang. Dignidade da pessoa humana e direitos fundamentais na Constituição Federal de 1988. 9. ed. Porto Alegre: Livraria do Advogado, 2011. 
SILVA, Rosane Leal da. Das redes ao processo: perspectiva normativa e jurisprudencial da violência sexual contra crianças e adolescentes na internet. In: VERONESE, Josiane Rose Petry. Direito da criança e do adolescente: novo curso - novos temas. 2. ed. Rio de Janeiro: Lumen Iuris, p. 501-540.

SOUZA, I. F. de. A responsabilidade compartilhada no Direito da Criança e Adolescente como dimensão da solidariedade: intersecção entre público e privado. Revista Brasileira de História \&amp; Ciências Sociais, [S. l.], v. 12, n. 24, p. 119-142, 2020. DOI: 10.14295/rbhcs.v12i24.11961. Disponível em: https://bit.ly/3FYtW8Y. Acesso em: 21 jun. 2021.

TRIPP, David. Pesquisa-ação: uma introdução metodológica. Educação e Pesquisa [online]. 2005, v. 31, n. 3, p. 443-466. Disponível em: https://doi.org/10.1590/S1517-97022005000300009. Acesso em: 20 jun. 2021.

VERONESE, Josiane Rose Petry. Os direitos da criança e do adolescente. São Paulo: LTr, 1999. 